
Representatives

For Release on Delivery

Expected at 10:00 a.m. EST

Wednesday, January 24, 2007

\section{POVERTY IN AMERICA}

\section{Consequences for Individuals and the Economy}

Statement of Sigurd R. Nilsen, Director

Education, Workforce, and Income Security Issues

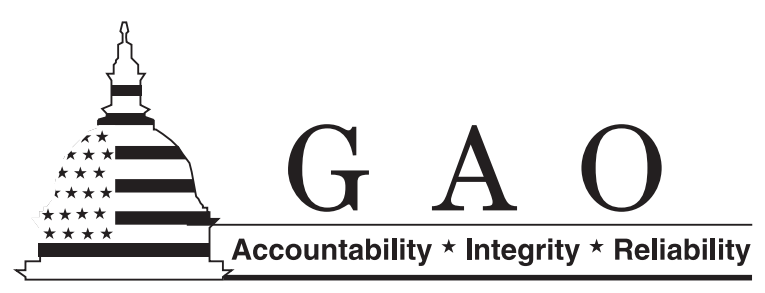




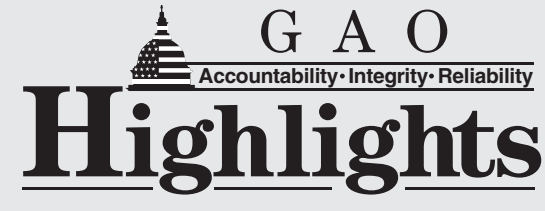

Highlights of GAO-07-343T, a testimony before the Chairman, Committee on Ways and Means, House of Representatives

\section{Why GAO Did This Study}

In 2005, 37 million people, approximately 13 percent of the total population, lived below the poverty line, as defined by the Census Bureau. Poverty imposes costs on the nation in terms of both programmatic outlays and productivity losses that can affect the economy as a whole. To better understand the potential range of effects of poverty, GAO was asked to examine (1) what the economic research tells us about the relationship between poverty and adverse social conditions, such as poor health outcomes, crime, and labor force attachment, and (2) what links economic research has found between poverty and economic growth. To answer these questions, GAO reviewed the economic literature by academic experts, think tanks, and government agencies, and reviewed additional literature by searching various databases for peerreviewed economic journals, specialty journals, and books. We also provided our draft report for review by experts on this topic.

www.gao.gov/cgi-bin/getrpt?GAO-07-343T.

To view the full product, including the scope and methodology, click on the link above. For more information, contact Sigurd R.

Nilsen at (202) 512-7215 or at

nilsens@gao.gov.

\section{POVERTY IN AMERICA}

\section{Consequences for Individuals and the Economy}

\section{What GAO Found}

Economic research suggests that individuals living in poverty face an increased risk of adverse outcomes, such as poor health and criminal activity, both of which may lead to reduced participation in the labor market. While the mechanisms by which poverty affects health are complex, some research suggests that adverse health outcomes can be due, in part, to limited access to health care as well as greater exposure to environmental hazards and engaging in risky behaviors. For example, some research has shown that increased availability of health insurance such as Medicaid for low-income mothers led to a decrease in infant mortality. Additionally, exposure to higher levels of air pollution from living in urban areas close to highways can lead to acute health conditions. Data suggest that engaging in risky behaviors, such as tobacco and alcohol use, a sedentary life-style, and a low consumption of nutritional foods, can account for some health disparities between lower and upper income groups. The economic research we reviewed also points to links between poverty and crime. For example, one study indicated that higher levels of unemployment are associated with higher levels of property crime. The relationship between poverty and adverse outcomes for individuals is complex, in part because most variables, like health status, can be both a cause and a result of poverty. These adverse outcomes affect individuals in many ways, including limiting their development of the skills, abilities, knowledge, and habits necessary to fully participate in the labor force.

Research shows that poverty can negatively affect economic growth by affecting the accumulation of human capital and rates of crime and social unrest. Economic theory has long suggested that human capital-that is, the education, work experience, training, and health of the workforce-is considered one of the fundamental drivers of economic growth. The conditions associated with poverty can work against this human capital development by limiting individuals' ability to remain healthy and develop skills, in turn decreasing the potential to contribute talents, ideas, and even labor to the economy. An educated labor force, for example, is better at learning, creating and implementing new technologies. Economic theory suggests that when poverty affects a significant portion of the population, these effects can extend to the society at large and produce slower rates of growth. Although historically research has focused mainly on the extent to which economic growth alleviates poverty, some recent empirical studies have begun to demonstrate that higher rates of poverty are associated with lower rates of growth in the economy as a whole. For example, areas with higher poverty rates experience, on average, slower per capita income growth rates than low-poverty areas. 
Mr. Chairman and Members of the Committee:

I am pleased to be here today to discuss the important topic of poverty and its effects on individuals and our economy. My testimony is drawn from our report Poverty in America: Economic Research Shows Adverse Impacts on Health Status and Other Social Conditions as well as the Economic Growth Rate (GAO-07-344), being released this morning. Our work looks at what the economic research tells us about the relationship between poverty and adverse social conditions, such as poor health outcomes, crime, and labor force attachment; and what links economic research has found between poverty and economic growth.

According to the Census Bureau, approximately 37 million people in the United States-nearly 13 percent of the total population-lived below the poverty line in $2005 .{ }^{1}$ This percentage was significantly larger for particular population groups, specifically children, minorities, and those living in certain geographic areas such as inner cities. The federal government spends billions of dollars on programs to assist low-income individuals and families. ${ }^{2}$ These programs included Medicaid, food stamps, Temporary Assistance for Needy Families (TANF), and the Earned Income Tax Credit (EITC), to name some of the largest. While some have taken issue with Census' official poverty measure and proposed alternative measures, it is generally recognized that poverty imposes costs on the nation as a whole, not merely in terms of programmatic outlays but also through lost productivity that can affect the overall economy.

In conducting our work, we reviewed the economic literature by academic experts, think tanks, and government agencies, which we collected from searches of various databases, peer-reviewed economic journals, specialty journals, and books. We also provided our draft report to four external reviewers. They are recognized experts who have conducted research and published on the topic of poverty and economic growth and whose work has recommended a variety of approaches and strategies to policymakers. We limited the scope of our work by looking at recent studies published since 1996, excluding anything older, with exceptions made for work that was considered seminal. Thus, our results are not an exhaustive or

${ }^{1}$ In 2005 the poverty threshold for a family of four was $\$ 19,971$.

${ }^{2}$ Congressional Research Service, Cash and Noncash Benefits for Persons with Limited Income: Eligibility Rules, Recipient and Expenditure Data, FY2002-FY2004 (Washington, D.C.: Mar. 27, 2006). 
historical treatment of the topic. Our review was primarily driven by the economic literature focused on the United States either exclusively or including other developed nations; studies from other disciplines were excluded unless they were captured in either the economic study under review or its bibliography. When we refer to poverty in the report, we are using an absolute measure, not a relative one. This means that, for the most part, the studies we reviewed typically used the official poverty line published by the Census Bureau as its benchmark. A few of the studies we reviewed used relative measures such as the poorest 10 percent of the population.

Our work was conducted between October 2006 and January 2007 according to generally accepted government auditing standards. Because we did not evaluate the policies, operations, or programs of any federal agency to develop the information presented in this report, and because we are not making any recommendations, we did not seek agency comments. However, we met with agency officials from the Departments of Commerce, Health and Human Services, Justice, and Labor to obtain information on research they or others had conducted related to our work objectives.

Economic research shows that poverty is associated with a number of adverse outcomes for individuals, such as poor health, crime, and reduced labor market participation, and has a negative impact on the economic growth rate. Some research suggests that adverse health outcomes are due, in part, to limited access to health care as well as exposure to environmental hazards and engaging in risky behaviors. The economic research we reviewed also suggests that poverty is associated with higher levels of certain types of crime. The relationship between poverty and adverse outcomes for individuals is complex, in part because most variables, like health status, can be both a cause and a result of poverty. Regardless of whether poverty is a cause or an effect, however, the conditions associated with poverty can work against the development of human capital - that is the ability of individuals to remain healthy and develop the skills, abilities, knowledge, and habits necessary to fully participate in the labor force. Human capital development is considered one of the fundamental drivers of economic growth. An educated labor force, for example, is better at learning, creating, and implementing new technologies. Economic theory suggests that when poverty affects a significant portion of the population, these effects can extend to the society at large and produce slower rates of growth. Though limited, 
empirical research has demonstrated that higher rates of poverty are associated with lower rates of growth in the economy as a whole.

\section{Background}

Economic growth is one of the indicators by which the well-being of the nation is typically measured, although recent discussions have focused on a broader set of indicators, such as poverty. Poverty in the United States is officially measured by the Census Bureau, which calculates the number of persons or households living below an established level of income deemed minimally adequate to support them. The federal government has a longstanding history of assisting individuals and families living in poverty by providing services and income transfers through numerous and various types of programs.
Measuring the Nation's

Well Being: Economic Growth and Other Indicators
Economic growth is typically defined as the increase in the value of goods and services produced by an economy; traditionally this growth has been measured by the percentage rate of increase in a country's gross domestic product, or GDP. The growth in GDP is a key measure by which policymakers estimate how well the economy is doing. However, it provides little information about how well individuals and households are faring.

Recently there has been a substantial amount of activity in the United States and elsewhere to develop a comprehensive set of key indicators for communities, states, and the nation that go beyond traditional economic measures. Many believe that such a system would better inform individuals, groups, and institutions on the nation as a whole. Poverty is one of these key indicators. Poverty, both narrowly and more broadly defined, is a characteristic of society that is frequently monitored and defined and measured in a number of ways. ${ }^{3}$

${ }^{3} \mathrm{GAO}$, Informing Our Nation: Improving How to Understand and Assess the USA's Position and Progress, GAO-05-1 (Washington, D.C., November 2004). 


\section{How Is Poverty Defined in the United States?}

The Census Bureau is responsible for establishing a poverty threshold amount each year; persons or families having income below this amount are, for statistical purposes, considered to be living in poverty. ${ }^{4}$ The threshold reflects estimates of the amount of money individuals and families of various sizes need to purchase goods and services deemed minimally adequate based on 1960s living standards, and is adjusted each year using the consumer price index. The poverty rate is the percentage of individuals in total or as part of various subgroups in the United States who are living on income below the threshold amounts.

Over the years, experts have debated whether or not the way in which the poverty threshold is calculated should be changed. Currently the calculation only accounts for pretax income and does not include noncash benefits and tax transfers, which, especially in recent years, have comprised larger portions of the assistance package to those who are lowincome. ${ }^{5}$ For example, food stamps and the Earned Income Tax Credit could provide a combined amount of assistance worth an estimated $\$ 5,000$ for working adults with children who earn approximately $\$ 12,000$ a year. ${ }^{6}$ If noncash benefits were included in a calculation of the poverty threshold, the number and percentage of individuals at or below the poverty line could change. In 1995, a National Academy of Sciences (NAS) panel recommended that changes be made to the threshold to count noncash benefits, tax credits, and taxes; deduct certain expenses from income such as child care and transportation; and adjust income levels according to an area's cost of living. ${ }^{7}$ In response, the Census Bureau published an experimental poverty measure in 1999 using the NAS recommendations in addition to its traditional measure but, to date, Census has not changed the official measure. ${ }^{8}$

\footnotetext{
${ }^{4}$ The U.S. Department of Health and Human Services (HHS) establishes poverty guidelines that are similar to the poverty thresholds but are used by HHS and other agencies for administering programs, such as determining program eligibility.

${ }^{5}$ Congressional Research Service, Poverty in the United States: 2005 (Washington, D.C.: Aug. 31, 2006).

${ }^{6}$ Danzinger, Sheldon, "Fighting Poverty Revisited: What Did Researchers Know 40 Years Ago? What Do We know Today?" Dec. 4, 2006.

${ }^{7}$ For a summary of the NAS panel recommendations see Congressional Research Service Report 95-539, Redefining Poverty in the United States: National Academy of Science Panel Recommendations, by Thomas R. Gabe (archived) (Washington, D.C.: 1995).

${ }^{8}$ U.S. Census Bureau, Poverty among Working Families: Findings from Experimental Poverty Measures (Washington, D.C.: Sept. 2000).
} 

people-were counted as living below the poverty line, a number that essentially remained unchanged from 2004. Poverty rates differ, however, by age, gender, race, and ethnicity and other factors. For example,

- Children: In 2005, 12.3 million children, or 17.1 percent of children under the age of 18, were counted as living in poverty. Children of color were at least three times more likely to be in poverty than those who were white: 34.2 percent of children who were African- American and 27.7 percent of children who were Hispanic lived below the poverty line compared to 9.5 percent of children who were white. ${ }^{9}$ AfricanAmerican children represented 15.2 percent and Hispanic children represented 19.9 percent of all children under the age of 18 in 2005.

- Racial and ethnic minorities: African-Americans and Hispanics have significantly higher rates of poverty than whites. In 2005, 24.9 percent of African-Americans and 22 percent of Hispanics lived in poverty compared to 8.3 percent for whites. African-Americans made up 12.5 percent of the total population while Hispanics accounted for 14.7 percent.

- Elderly: The elderly have lower rates of poverty than other groups. For example, 10.1 percent of adults aged 65 or older lived in poverty. The elderly represented 12.1 percent of the total U.S. population in 2005.

Poverty rates also differ depending on geographical location and for urban and nonurban areas. Poverty rates for urban areas were double those in suburbs, 17 percent compared to 9.3 percent. Poverty rates in the South were the highest at 14 percent; the West had a rate of 12.6 percent, followed by the Midwest with 11.4 percent and the Northeast at 11.3 percent. $^{10}$

\footnotetext{
${ }^{9}$ Beginning in March 2003, the Census Bureau allowed survey respondents to identify themselves as belonging to one or more racial groups. In prior years, respondents could select only one racial category. Consequently, poverty statistics for different racial groups for 2002 and after are not directly comparable to earlier years' data. The term "blacks and white" refers to persons who identified with only one single racial group. The term "Hispanic" refers to individuals' ethnic, as opposed to racial, identification. Hispanics may be of any race.

${ }^{10}$ Congressional Research Service, Poverty in the United States: 2005 (Washington, D.C.: Aug. 31, 2006).
} 
The Role of the Federal Government
The U.S. government has a long history of efforts to improve the conditions of those living with severely limited resources and income. Presidents, Congress, and other policymakers have actively sought to help citizens who were poor, beginning as early as the 1850s through the more recent efforts established through welfare reform initiatives enacted in 1996.

Over the years, the policy approaches used to help low-income individuals and families have varied. For example, in the1960s federal programs focused on increasing the education and training of those living in poverty. In the 1970s, policy reflected a more income-oriented approach with the introduction of several comprehensive federal assistance plans. More recently, welfare reform efforts have emphasized the role of individual responsibility and behaviors in areas such as family formation and work to assist people in becoming self-sufficient. Although alleviating poverty and the conditions associated with it has long been a federal priority, approaches to developing effective interventions have sometimes been controversial, as evidenced by the diversity of federal programs in existence and the ways in which they have evolved over time.

Currently, the federal government, often in partnership with the states, has created an array of programs to assist low-income individuals and families. According to a recent study by the Congressional Research Service (CRS), the federal government spent over $\$ 400$ billion on 84 programs in 2004 that provided cash and noncash benefits to individuals and families with limited income. These programs cover a broad array of services: Examples include income supports or transfers such as the Earned Income Tax Credit and TANF; work supports such as subsidized child care and job training; health supports and insurance through programs like the State Children's Health Insurance Program (SCHIP) and Medicaid; and other social services such as food, housing, and utility assistance. Table 1 provides a list of examples of selected programs. 
Table 1: Selected Examples of Federal Cash and Noncash Assistance to Low-Income Families and Individuals, Fiscal Year 2004

\begin{tabular}{|c|c|c|c|}
\hline Purpose & Program & $\begin{array}{l}\text { Federal } \\
\text { cash outlay }\end{array}$ & Program description \\
\hline \multirow[t]{2}{*}{ Cash aid } & $\begin{array}{l}\text { Temporary Assistance for Needy } \\
\text { Families (TANF) }\end{array}$ & $\$ 10.4$ billion $^{a}$ & $\begin{array}{l}\text { Permits a state to give ongoing basic cash aid to } \\
\text { families that include a minors or a pregnant woman. } \\
\text { Work and other requirements must be met. }\end{array}$ \\
\hline & Earned Income Tax Credit (EITC) & $\$ 37.9$ billion $^{b}$ & $\begin{array}{l}\text { Provides a refundable credit to workers with and without } \\
\text { children. }\end{array}$ \\
\hline
\end{tabular}

Food and nutrition Food Stamp Program

Special Supplemental Nutrition Program for Women, Infants and Children (WIC)

\begin{tabular}{|c|c|c|c|}
\hline \multirow[t]{2}{*}{ Medical } & Medicaid & $\$ 176$ billion & $\begin{array}{l}\text { Provides payments to health care providers in full or via } \\
\text { co-pay for eligible low-income families and individuals } \\
\text { and for long-term care to eligible individuals who are } \\
\text { aged or disabled. }\end{array}$ \\
\hline & $\begin{array}{l}\text { State Children's Health Insurance } \\
\text { Program (SCHIP) }\end{array}$ & $\$ 4.6$ billion $^{d}$ & $\begin{array}{l}\text { Provides federal matching funds for states and } \\
\text { territories to provide health insurance to targeted low- } \\
\text { income children. }\end{array}$ \\
\hline \multirow[t]{2}{*}{ Educational } & Federal Pell Grant Program & $\$ 12$ billion & $\begin{array}{l}\text { Provides assistance to undergraduate students who } \\
\text { meet a certain needs test and are enrolled in an eligible } \\
\text { institution of postsecondary education. }\end{array}$ \\
\hline & Head Start & $\$ 6.8$ billion $^{e}$ & $\begin{array}{l}\text { Provides comprehensive services to targeted low- } \\
\text { income children. Services include educational, medical, } \\
\text { dental, nutritional, and social services. }\end{array}$ \\
\hline Housing & $\begin{array}{l}\text { Section } 8 \text { Low-Income Housing } \\
\text { Assistance }\end{array}$ & $\$ 22.4$ billion & $\begin{array}{l}\text { Provides rental assistance through vouchers or rental } \\
\text { subsidies to eligible low-income families or single } \\
\text { persons. }\end{array}$ \\
\hline \multirow[t]{2}{*}{ Services } & $\begin{array}{l}\text { Child Care and Development Block } \\
\text { Grant (CCDBG) }\end{array}$ & $\$ 6.9$ billion & Provides funding to low-income parents for child care. \\
\hline & $\begin{array}{l}\text { Social Services Block Grant (SSBG) } \\
\text { (Title XX) }\end{array}$ & $\$ 1.7$ billion & $\begin{array}{l}\text { Provides funding to assist states in providing social } \\
\text { services to eligible low-income individuals or families. }\end{array}$ \\
\hline Jobs & Job Corps & $\$ 1.5$ billion & $\begin{array}{l}\text { Provides no-cost training and education to low-income } \\
\text { individuals ages } 16-24 \text { while providing a monthly } \\
\text { allowance payment. }\end{array}$ \\
\hline Energy & $\begin{array}{l}\text { Low-Income Home Energy Assistance } \\
\text { Program (LIHEAP) }\end{array}$ & $\$ 1.9$ billion & $\begin{array}{l}\text { Provides assistance to low-income home owners and } \\
\text { renters to help meet energy needs such as heating and } \\
\text { cooling. }\end{array}$ \\
\hline
\end{tabular}

Source: For a full list of federal programs, see Cash and Noncash Benefits for Persons with Limited Income: Eligibility Rules, Recipient and Expenditure Data, FY2002-FY2004; Washington D.C. 2006.
$\$ 27.2$ billion $^{c} \quad$ Provides certain allotments to individuals for purchasing of food items, based upon the individual's level of eligibility/need.

\$4.5 million Provides benefits for low-income mothers, infants, and children considered to be at "nutritional risk." and for long-term care to eligible individuals who are territories to provide health insurance to targeted lowProvides assistance to undergraduate students who meet a certain needs test and are enrolled in an eligible institution of postsecondary education. income children. Services include educational, medical, , nutritional, subsidies to eligible low-income families or single persons. services to eligible low-income individuals or families. individuals ages 16-24 while providing a monthly Provides assistance to low-income home owners and renters to help meet energy needs such as heating and cooling.
Provides funding to assist states in providing social 
${ }^{\mathrm{a}}$ Federal outlay figures in table 1 are from fiscal year 2004, as reflected in the CRS report from which they are taken, sourced above. Some exceptions apply and are noted. The TANF figure, $\$ 10.4$ billion, is the estimated total of federal and state expenditures combined for only TANF cash aid in fiscal year 2004. This figure does not include other combined federal and state funding for the following: TANF child care, estimated at $\$ 2.5$ billion in fiscal year 2004; TANF work programs and activities, estimated at $\$ 2.2$ billion in fiscal year 2004; and TANF services estimated at \$6.3 billion in fiscal year 2004.

${ }^{b}$ EITC federal outlay total of $\$ 37.9$ billion is for fiscal year 2003 as reported in GAO, Means Tested Programs: Information on Program Access Can Be an Important Management Tool, GAO-05-221 (Washington, D.C. March 2005).

${ }^{\circ}$ For more on the Food Stamp Program, see GAO-05-839R, (Washington, D.C.: June 30, 2005).

${ }^{\mathrm{d}}$ For more on SCHIP federal outlay figure of $\$ 4.6$ billion, see GAO-05-839R.

${ }^{\mathrm{e} H e a d}$ Start federal outlay total of $\$ 6.8$ billion is for fiscal year 2005 .

Economic Research Links Poverty with Adverse Outcomes for Individuals Such as Poor Health and Crime
Economic research suggests that individuals living in poverty face an increased risk for adverse outcomes, such as poor health, criminal activity, and low participation in the workforce. The adverse outcomes that are associated with poverty tend to limit the development of skills and abilities individuals need to contribute productively to the economy through work, and this in turn, results in low incomes. The relationship between poverty and outcomes for individuals is complex, in part because most variables, like health status, can be both a cause and a result of poverty. The direction of the causality can have important policy implications. To the extent that poor health causes poverty, and not the other way around, then alleviating poverty may not improve health.
Individuals Living in

Poverty Experience Higher

Rates of Adverse Health

Outcomes, in Part because

of Limited Access to

Health Care,

Environmental Hazards, and Risky Behaviors
Health outcomes are worse for individuals with low incomes than for their more affluent counterparts. Lower-income individuals experience higher rates of chronic illness, disease, and disabilities, and also die younger than those who have higher incomes. ${ }^{11}$ As reported by the National Center on Health Statistics, individuals living in poverty are more likely than their affluent counterparts to experience fair or poor health, or suffer from conditions that limit their everyday activities (fig.1). They also report higher rates of chronic conditions such as hypertension, high blood pressure, and elevated serum cholesterol, which can be predictors of more acute conditions in the future. Life expectancies for individuals in poor families as compared to nonpoor families also differ significantly. One study showed that individuals with low incomes had life expectancies 25 percent lower than those with higher incomes. ${ }^{12}$ Other research

\footnotetext{
${ }^{11}$ Centers for Disease Control and Prevention, Health, United States, 2006; 1998 (Hyattsville, Maryland).

${ }^{12}$ Deaton, Angus, "Policy Implications of The Gradient of Health and Wealth," Health Affairs, Vol. 21., No.2, March 2002.
} 
suggests that an individual's household wealth predicts the amount of functionality of that individual in retirement. ${ }^{13}$

\section{Figure 1: Selected Health Indicators by Poverty Status}

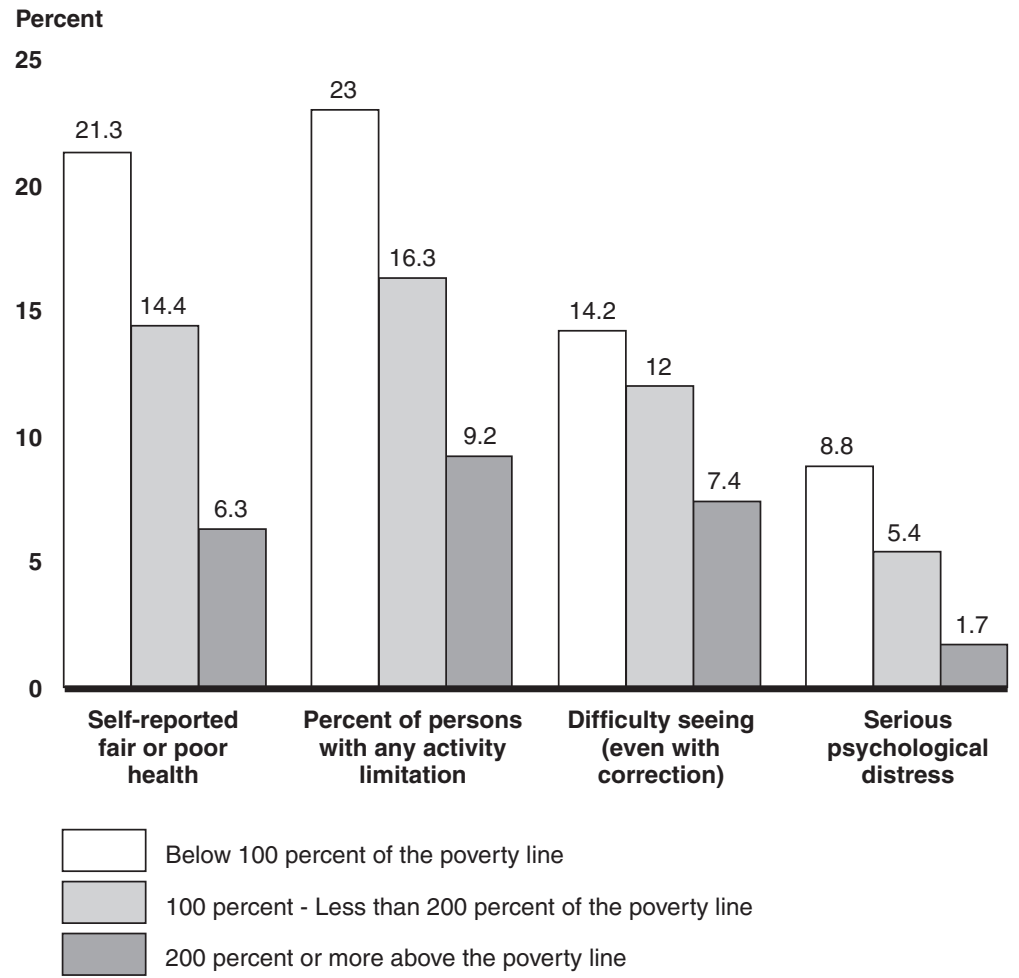

Source: National Center for Health Statistics, Health, United States, 2006 with Chartbook on Trends in the Health of Americans (Hyattsville, Maryland: 2006).

Research suggests that part of the reason that those in poverty have poor health outcomes is that they have less access to health insurance and thus less access to health care, particularly preventive care, than others who are nonpoor. Very low-income individuals were three times as likely not to have health insurance than those with higher incomes, which may lead to reduced access to and utilization of health care (fig. 2).

\footnotetext{
${ }^{13}$ Smith, James, and Raynard Kington, "Demographic and Economic Correlates of Health in Old Age.” Demography, Vol. 34, No. 1, 1997.
} 
Figure 2: Percentage of Population with No Health Insurance (Private or Medicaid) by Poverty Status

Percent

35

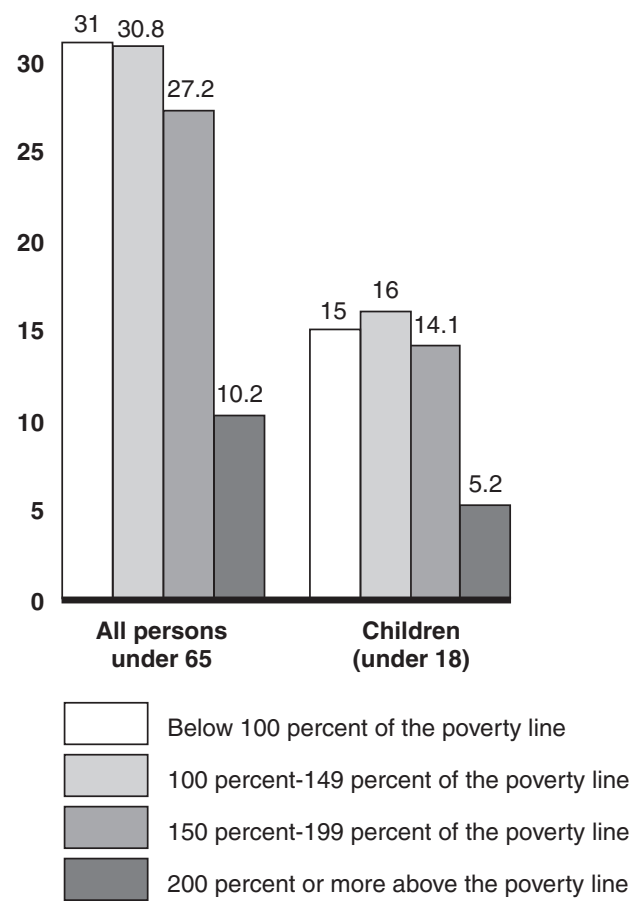

Source: National Center for Health Statistics, Health, United States, 2006 with Chartbook on Trends in the Health of Americans (Hyattsville, Maryland: 2006).

Data show that those who are poor with no health insurance access the health system less often than those who are either insured or wealthier when measured by one indicator of health care access: visits to the doctor. For example, data from the National Center on Health Statistics show that children in families with income below the poverty line who were continuously without any type of health insurance were three to four times more likely to have not visited a doctor in the last 12 months than children in similar economic circumstances who were insured (fig. 3). Research also suggests that a link between income and health exists independent of health insurance coverage. Figure 3 also shows that while children who are uninsured but in wealthier families visit the doctor fewer times than those who are insured, they still go more often than children who are uninsured but living in poverty. 
Figure 3: No Visits to Any Health Provider in the Past 12 Months (Children under 18 Years of Age) by Level of Insurance

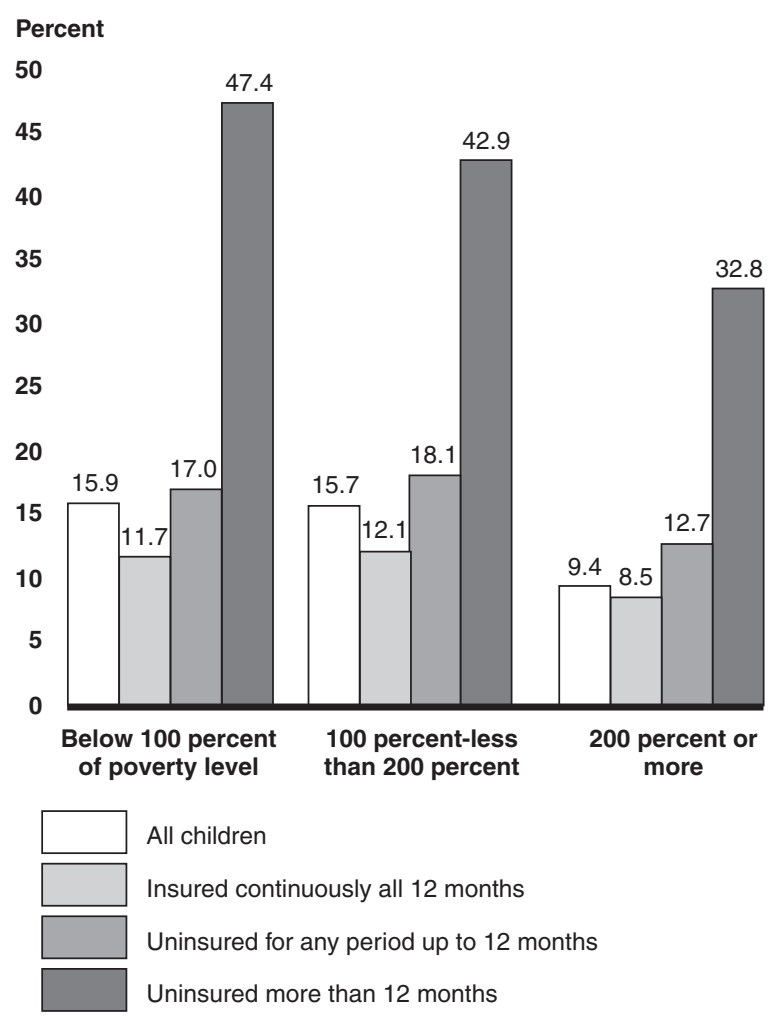

Source: National Center for Health Statistics, Health, United States, 2006 with Chartbook on Trends in the Health of Americans (Hyattsville, Maryland: 2006).

Some research examining government health insurance suggests that increased health insurance availability improves health outcomes.

Economists have studied the expansion of Medicaid, which provides health insurance to those with low income. They found that Medicaid's expansion of coverage, which occurred between 1979 and 1992, increased the availability of insurance and improved children's health outcomes. For example, one study found that a 30 percentage point increase in eligibility for mothers aged 15-44 translated into a decrease in infant mortality of 8.5 percent. ${ }^{14}$ Another study looked at the impact of health insurance coverage

\footnotetext{
${ }^{14}$ Currie, Janet, and Jonathan Gruber, "Saving Babies: The Efficacy and Cost of Recent Changes in the Medicaid Eligibility of Pregnant Women," The Journal of Political Economy, Vol. 104, No. 6, December 1996.
} 
through Medicare and its effects on the health of the elderly and also found a statistically significant though modest impact. ${ }^{15}$ There is some evidence that variations in health insurance coverage do not explain all the differences in health outcomes. A study done in Canada found improvements in children's health with increases in income, even though Canada offers universal health insurance coverage for hospital services, indicating that health insurance is only part of the story. ${ }^{16}$

Although there is a connection among poverty, having health insurance, and health outcomes, having health insurance is often associated with other attributes of an individual, thus making it difficult to isolate the direct effect of health insurance alone. Most individuals in the United States are either self-insured or insured through their employer. If those who are uninsured have lower levels of education, as do individuals with low income, differences in health between the insured and uninsured might be due to level or quality of education, and not necessarily insurance. $^{17}$

Another reason that individuals living in poverty may have more negative health outcomes is because they are more likely to live and work in areas that expose them to environmental hazards such as pollution or substandard housing. Some researchers have found that because poorer neighborhoods may be located closer to industrial areas or highways than more affluent neighborhoods, there tend to be higher levels of pollution in

\footnotetext{
${ }^{15}$ Card, David, et. al., "The Impact of Nearly Universal Insurance Coverage on Health Care Utilization and Health: Evidence from Medicare" National Bureau of Economic Research, Working Paper 10365. NBER, March 2004.

${ }^{16}$ Currie, Janet, and Mark Stabile, "Socioeconomic Status and Child Health: Why Is the Relationship Stronger for Older Children.” American Economic Review, Vol. 93, No. 5, December 2003.

${ }^{17}$ Additionally, differences in individual health outcomes can sometimes be explained by other factors that may be associated with poverty, but are difficult to detect, such as risk aversion.
} 
lower-income neighborhoods. ${ }^{18}$ The Institute of Medicine concluded that minority and low-income communities had disproportionately higher exposure to environmental hazards than the general population, and because of their impoverished conditions were less able to effectively change these conditions. ${ }^{19}$

The link between poverty and health outcomes may also be explained by lifestyle issues associated with poverty. Sedentary life-style: the use of alcohol and drugs; as well as lower consumption of fiber, fresh fruits, and vegetables are some of the behaviors that have been associated with lower socioeconomic status. ${ }^{20}$ Cigarette smoking is also more common among adults who live below the poverty line than among those above it, about 30 percent compared to 21 percent. ${ }^{21}$ Similarly, problems with being overweight and obese are common among those with low family incomes, although most prevalent in women: Women with incomes below 130 percent of the poverty line were 50 percent more likely to be obese than those with incomes above this amount. ${ }^{22}$ Figure 4 shows that people living

\footnotetext{
${ }^{18}$ While much of the specific biological mechanism by which air pollution might affect health is still unknown, some recent research by economists has noted a link between pollution and health, especially for infants. Currie and Neidell (2005) find that the decrease in the level of carbon monoxide in California in the 1990s had a significant effect on reducing infant mortality. See Currie, Janet, and Matthew Neidell, "Air Pollution and Infant Health: What Can We Learn From California's Recent Experience?" Quarterly Journal of Economics, 120 (3), 2005. Similarly, Chay and Greenstone (2003) find that the reduction in total suspended particulates due to the 1970 Clean Air Act had a significant impact on infant mortality. See Chay, Kenneth, and Michael Greenstone, "Air Quality, Infant Mortality, and the Clean Air Act of 1970." National Bureau of Economic Research, Working Paper No. 10053. NBER, 2003.

${ }^{19}$ Institute of Medicine, Committee on Environmental Justice, "Toward Environmental Justice: Research, Education, and Health Policy Needs”, (Washington, D.C.: 1999), p.6.

${ }^{20}$ Adler, Nancy E., and Katherine Newman, "Socioeconomic Disparities in Health: Pathways and Policies." Health Affairs, Vol. 21 No. 2, 2002. See also Deaton, Angus. "Policy Implications of the Gradient of Health and Wealth." Health Affairs, Vol. 21, No.2: 2002.

${ }^{21}$ Centers for Disease Control and Prevention, Tobacco Use among Adults-United States, 2005. Morbidity and Mortality Weekly Report , 2006; 55(42): 1145-1148. Some research suggests that part of the reason why smoking rates are higher may be peer effects, especially among youth smokers. See DeCicca, Phillip, Donald Kenkel, and Alan Mathios, "Racial Difference in the Determinants of Smoking Onset." Journal of Risk and Uncertainty. Boston: 2000. Vol. 21, Iss. 2/3; p311. Other studies have shown that educational attainment can affect smoking use as well. See DeCicca, Philip, Donald Kenkel, and Alan Mathios,"Putting Out the Fires: Will Higher Taxes Reduce the Onset of Youth Smoking?" Journal of Political Economy. Chicago 2002.Vol.110, Iss.1; p. 144.
}

${ }^{22}$ U.S. Public Health Service, Surgeon General's Call To Action to Prevent and Decrease Overweight and Obesity 2001, Washington, DC, pp. 13-14. 
in poverty are less likely to engage in regular, leisure-time physical activity than others and are somewhat more likely to be obese, and children in poverty are somewhat more likely to be overweight than children living above the poverty line. In addition, there is also evidence to suggest a link among poverty, stress, and adverse health outcomes, such as compromised immune systems. ${ }^{23}$

Figure 4: Percentage of Population Who Have a Sedentary Lifestyle, Are Overweight, or Are Obese, by Poverty Status

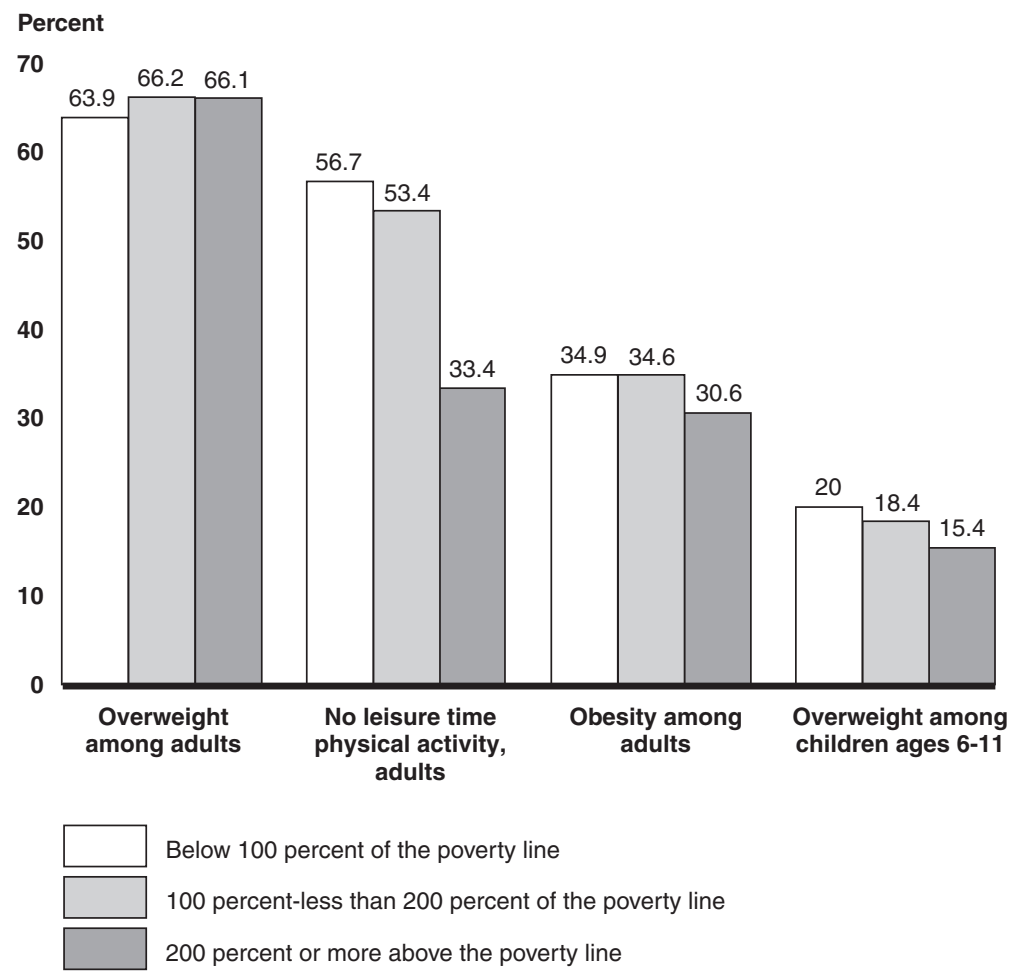

Source: National Center for Health Statistics, Health, United States, 2006 with Chartbook on Trends in the Health of Americans (Hyattsville, Maryland: 2006).

\footnotetext{
${ }^{23}$ While access to care, behavior, and environmental factors are some of the most commonly offered reasons for the relationship between poverty and health, recent literature has suggested other alternative theories, of which there is less of a research tradition. These include the effect of short exposures to health shocks as a result of poverty, such as poor nutrition or increased adrenalin due to higher levels of stress, and psycho-social stress that leads to problems with the immune system. See Smith, James P., "Healthy Bodies and Thick Wallets: The Dual Relation between Health and Economic Status.” The Journal of Economic Perspectives, Vol. 13, No. 2, 1999.
} 
While evidence shows how poverty could result in poor health, the opposite could also be true. For example, a health condition could result, over time, in restricting an individual's employment, resulting in lower income. Additionally, the relationship between poverty and health outcomes could also vary by demographic group. ${ }^{24}$ Failing health, for example, can be more directly associated with household income for middle-aged and older individuals than with children, since adults are typically the ones who work.

Economic Research Shows an Association between Poverty and Crime
Just as research has established a link between poverty and adverse health outcomes, evidence suggests a link between poverty and crime. Economic theory predicts that low wages or unemployment makes crime more attractive, even with the risks of arrest and incarceration, because of lower returns to an individual through legal activities.$^{25}$ While more mixed, empirical research provides support for this. For example, one study shows that higher levels of unemployment are associated with higher levels of property crime, but is less conclusive in predicting violent crime. ${ }^{26}$ Another study has shown that both wages and unemployment affect crime, but that wages play a larger role. ${ }^{27}$

Research has found that peer influence and neighborhood effects may also lead to increased criminal behavior by residents. Having many peers that engage in negative behavior may reduce social stigma surrounding that behavior. ${ }^{28}$ In addition, increased crime in an area may decrease the

\footnotetext{
${ }^{24}$ It is not clear whether these adverse outcomes occur with greater frequency among all individuals living in households below the poverty line or only among those experiencing extreme poverty; those who experience poverty during critical development stages, such as infancy or early childhood; or those who experience long bouts of poverty.

${ }^{25}$ Criminal behavior has been measured by reports to the police in an area, self-reported crime by individuals in surveys or arrests, as well as other measures. See also Freeman, Richard, "Why Do So Many Young American Men Commit Crimes and What Might We Do About It?” Journal of Economic Perspectives, Vol. 10, No. 1: Winter 2006.

${ }^{26}$ Raphael, Steven, and Rudolf Winter-Ebner, "Identifying the Effect of Unemployment on Crime." Journal of Law and Economics, Vol. XLIV. 2001.

${ }^{27}$ Gould, Eric D., Bruce A. Weinberg, and David B. Mustard, "Crime Rates and Local Labor Market Opportunities in the United States: 1979-1997. Review of Economics and Statistics, 84 (1): 2002.

${ }^{28}$ Katz, Lawrence F., Jeffrey R. Kling, and Jeffrey B. Liebman, "Moving to Opportunity in Boston: Early Results of a Randomized Mobility Experiment." Quarterly Journal of Economics, May 2001.
} 
chances that any particular criminal activity will result in an arrest. Other research suggests that the neighborhood itself, independent of the characteristics of the individuals who live in it, affects criminal behavior. ${ }^{29}$ One study found that arrest rates were lower among young people from low-income families who were given a voucher to live in a low-poverty neighborhood, as opposed to their peers who stayed in high-poverty neighborhoods. The most notable decrease was in arrests for violent crimes; the results for property crimes, however, were mixed, with arrest rates increasing for males and decreasing for females. ${ }^{30}$

Adverse Outcomes, Such
as Poor Health and Low
Educational Attainment,
Lead to Reduced
Participation in the Labor
Market

Adverse Outcomes, Such as Poor Health and Low Educational Attainment, Lead to Reduced Market

\begin{abstract}
Regardless of whether poverty is a cause or an effect, the conditions associated with poverty limit the ability of low-income individuals to develop the skills, abilities, knowledge, and habits necessary to fully participate in the labor force, in turn leading to lower incomes. According to 2000 Census data, people aged 20-64 with income above the poverty line in 1999 were almost twice as likely to be employed as compared to those with incomes below it. ${ }^{31}$ Some of the reasons for these outcomes include educational attainment and health status.
\end{abstract}

\footnotetext{
${ }^{29}$ However, a challenge that researchers face is that, almost by definition, many individuals share the same characteristics in a neighborhood. Therefore, it is difficult to determine whether it is the characteristic of the individual or the neighborhood that is the source of the behavior.

${ }^{30} \mathrm{Http} / / / \mathrm{www} . h u d u s e r . o r g /$ publications/fairhsg/MTODemData.html and http://www.hud.gov/prodesc/mto.cfm . Some economists have used data from the Movingto-Opportunity experiment as a way to attribute causality. Moving-to-Opportunity is a research demonstration in which a number of families, chosen randomly, within five public housing authorities were given housing vouchers to be used in low-poverty neighborhoods. Another group of families acted as the control, and were not given the vouchers. Using these data, some economists have compared the outcomes for children whose families received the vouchers and those that did not. To some extent, the results have confirmed that neighborhood, independent of individual characteristics, affects criminal behavior, but the results have also been mixed. Using data from the randomized housing experiment, Ludwig, Duncan, and Hirschfeld (2001) found that the housing vouchers reduced violent arrests by teens, but may have increased the number of property arrests. Kling, Ludwig, and Katz (2005) also used the Moving-to-Opportunity data, but looked for differential effects by gender. The authors found that for females, there were large reductions in the amount of arrests for both property and violent crime, when compared to those for the control group. For males, there were reductions in violent arrests, but proportionally smaller than the drops for females. In addition, there were significant increases in the rate of property arrests.

${ }^{31}$ U.S. Census Bureau, Employment Status: 2000, Census 2000 Brief (Washington, D.C., August 2003), p.4
} 
Poverty is associated with lower educational quality and attainment, both of which can affect labor market outcomes. Research has consistently demonstrated that the quality and level of education attained by lowerincome children is substantially below those for children from middle- or upper-income families. Moreover, high school dropout rates in 2004 were four times higher for students from low-income families than those in high-income families. ${ }^{32}$ Those with less than a high school degree have unemployment rates almost three times greater than those with a college degree, 7.6 percent compared to 2.6 percent in 2005 . And the percentage of low-income students who attend college immediately after high school is significantly lower than for their wealthier counterparts: 49 percent compared to 78 percent. $^{33}$

A significant body of economic research directly links adverse health outcomes, which are also associated with low incomes, with the quality and quantity of labor that the individual is able to offer to the workforce. Many studies that have examined the relationship among individual adult health and wages, labor force participation, and job choice have documented positive empirical relationships among health and wages, earnings, and hours of work..$^{34}$ Although there is no consensus about the exact magnitude of the effects, the empirical literature suggests that poor health reduces the capacity to work and has substantive effects on wages, labor force participation, and job choice, meaning that poor health is associated with low income.

\footnotetext{
${ }^{32}$ National Center for Education Statistics, U.S. Department of Education, Dropout Rates in the United States: 2004, (Washington, D.C. November 2006), p. 4.

${ }^{33}$ Choy, Susan, "College Access and Affordability," Education Statistics Quarterly, Vol. 1, Issue 2, Topic: Postsecondary Education.

${ }^{34}$ Several methodological challenges exist in this literature: For example, many of these findings could reflect the effect of income on health rather than vice versa. In addition, results are highly sensitive to the measures of health that are used, with self-reported health status subject to several forms of bias, some of which could overstate the relationship between income and health, and others of which could understate the relationship. For example, individuals who have reduced their hours of work or left the labor force may be more likely to report poor health, in order to justify their reduced labor supply or because government programs provide incentives to report disability; this would lead to an upward bias in the estimated relationship between income and health. On the other hand, it is possible that higher-income individuals, who on average have greater health care utilization, may be more likely to be diagnosed with certain conditions simply because of their greater access to health care. This would lead to a downward bias in the estimated relationship between income and health.
} 
Research also demonstrates that poor childhood health has substantial effects on children's future outcomes as adults. Some research, for example, shows that low birth weight is correlated with a low health status later in life. Research also suggests that poor childhood health is associated with reduced educational attainment and reduced cognitive development. Reduced educational attainment may in turn have a causal effect not only on future wages as discussed above but also on adult health if the more educated are better able to process health information or make more informed choices about their health care or if education makes people more "future oriented" by helping them think about the consequences of their choices. In addition, some research shows that poor childhood health is predictive of poor adult health and poor adult economic status in middle age, even after controlling for educational attainment.

\section{Economic Research Suggests a Negative Association between Poverty and Economic Growth}

The economic literature suggests that poverty not only affects individuals but can also create larger challenges for economic growth. Traditionally, research has focused on the importance of economic growth for generating rising living standards and alleviating poverty, but more recently it has examined the reverse, the impact of poverty on economic growth. In the United States, poverty can impact economic growth by affecting the accumulation of human capital and rates of crime and social unrest. While the empirical research is limited, it points to the negative association between poverty and economic growth consistent with the theoretical literature's conclusion that higher rates of poverty can result in lower rates of growth.

Research has shown that accumulation of human capital is one of the fundamental drivers of economic growth. ${ }^{35}$ Human capital consists of the

\footnotetext{
${ }^{35}$ Economic models that consider human capital to be a fundamental driver of economic growth are commonly referred to as endogenous growth models, although the more traditional neoclassical model has also been augmented to include the role of human capital. Endogenous growth theory posits technological growth as occurring through dynamics inside the model. Although there are several competing models, crucial importance in each is given to the production of new technologies and human capital. While the major point these models emphasize is that human capital is the driving force behind growth, the actual modeling of the relationship is still a controversial issue in the economic literature. Some growth models assert that the driving force behind economic growth is the rate of accumulation of human capital, in which the rate of economic growth is proportional to the rate of accumulation of human capital. Another approach considers that high levels of human capital, as embodied in the level of the educational attainment of the workforce, increases the capacity of individuals to innovate (discover new technology) or to adopt new technology.
} 
skills, abilities, talents, and knowledge of individuals as used in employment. The accumulation of human capital is generally held to be a function of the education level, work experience, training, and healthiness of the workforce ${ }^{36}$ Therefore, schooling at the secondary and higher levels is a key component for building an educated labor force that is better at learning, creating, and implementing new technologies. Health is also an important component of human capital, as it can enhance workers' productivity by increasing their physical capacities, such as strength and endurance, as well as mental capacities, such as cognitive functioning and reasoning ability. Improved health increases workforce productivity by reducing incapacity, disability, and the number of days lost to sick leave, and increasing the opportunities to accumulate work experience. Further, good health helps improve education by increasing levels of schooling and scholastic performance.

The accumulation of human capital can be diminished when significant portions of the population have experienced long periods of poverty, or were living in poverty at a critical developmental juncture. For example, recent research has found that the distinct slowdown in some measures of human capital development is most heavily concentrated among youth from impoverished backgrounds. When individuals who have experienced poverty enter the workforce, their contributions may be restricted or minimal, while others may not enter the workforce in a significant way. Not only is the productive capability of some citizens lost, but their purchasing power and savings, which could be channeled into productive investments, is forgone as well.

In addition to the effects of poverty on human capital, some economic literature suggests that poverty can affect economic growth to the extent that it is associated with crime, violence, and social unrest. According to some theories, when citizens engage in unproductive criminal activities they deter others from making productive investments or their actions force others to divert resources toward defensive activities and expenditures. The increased risk due to insecurity can unfavorably affect

\footnotetext{
${ }^{36}$ In general, economists regard expenditures on education, training, medical care, and so on as investments in human capital. Collectively, theoretical growth models suggest economic growth results from improvements in human capital as embodied in the skills and experience of the labor force; from expansion of physical capital in the form of plant and equipment; and from progress in science, engineering, and management that generates technological advance. While many variables have been empirically tested, only a few have been accepted as being statistically significant in explaining growth. The role of human capital is now almost universally regarded as being indispensable in this respect.
} 
investment decisions - and hence economic growth—in areas afflicted by concentrated poverty. Although such theories link poverty to human capital deficiencies and criminal activity, the magnitude of their impact on economic growth for an economy such as the United States is unclear at this time.$^{37}$ In addition, people living in impoverished conditions generate budgetary costs for the federal government, which spends billions of dollars on programs to assist low-income individuals and families. Alleviating these conditions would allow the federal government to redirect these resources toward other purposes.

While economic theory provides a guide to understanding how poverty might compromise economic growth, empirical researchers have not as extensively studied poverty as a determinant of growth in the United States. Empirical evidence on the United States and other rich nations is quite limited, but some recent studies support a negative association between poverty and economic growth. For example, some research finds that economic growth is slower in U.S. metropolitan areas characterized by higher rates of poverty than those with lower rates of poverty. ${ }^{38}$ Another study, using data from 21 wealthy countries, has found a similar negative relationship between poverty and economic growth. ${ }^{39}$

Concluding Observations
Maintaining and enhancing economic growth is a national priority that touches on all aspects of federal decision making. As the nation moves forward in thinking about how to address the major challenges it will face

\footnotetext{
${ }^{37}$ Human capital deficits experienced by some impoverished individuals cannot always be attributed to experience of poverty. In some cases, low education attainment and poor health, although associated with poverty, may actually be caused by some other factor that is also responsible for poverty. In this case, poverty would be a symptom rather than a cause (i.e., poor health, poor choices, or addiction may erode human capital potential and cause poverty). Similarly, most poor people do not commit crimes, and those that do may be motivated by forces unrelated to their incomes.

${ }^{38}$ The relationship is not always statistically significant in all regions. Statistical insignificance in some cases might be more attributable to data issues such as sample size or multicollinearity rather than an indication of nonrelationship between poverty and income growth in various regions. See S. Dev Bhatta, "Are Inequality and Poverty Harmful for Economic Growth," Journal of Urban Affairs, 22 (3-4): 2001. This study provides, arguably, a better comparison group than cross-country studies, since metropolitan statistical areas in the United States are at relatively similar stages of development.
}

${ }^{39}$ Voitchovsky, S., "Does the Profile of Income Inequality Matter for Economic Growth? Distinguishing between the Effects of Inequality in Different Parts of the Income Distribution." Journal of Economic Growth, Vol.10.: 2005. 
in the twenty-first century, the impact of specific policies on economic growth will factor into decisions on topics as far ranging as taxes, support for scientific and technical innovation, retirement and disability, health care, education and employment. To the extent that empirical research can shed light on the factors that affect economic growth, this information can guide policymakers in allocating resources, setting priorities, and planning strategically for our nation's future.

Economists have long recognized the strong association between poverty and a range of adverse outcomes for individuals, and empirical research, while limited, has also begun to help us better understand the impact of poverty on a nation's economic growth. The interrelationships between poverty and various adverse social outcomes are complex, and our understanding of these relationships can lead to vastly different conclusions regarding appropriate interventions to address each specific outcome. Furthermore, any such interventions could take years, or even a generation, to yield significant and lasting results, as the greatest impacts are likely to be seen among children. Nevertheless, whatever the underlying causes of poverty may be, economic research suggests that improvements in the health, neighborhoods, education, and skills of those living in poverty could have impacts far beyond individuals and families, potentially improving the economic well-being of the nation as a whole.

This concludes my statement, Mr. Chairman. I would be happy to respond to any questions that you or other members of the committee may have. 


\section{Contact and Acknowledgments}

GAO Contact $\quad$ Sigurd R. Nilsen, (202) 512-7215 or nilsens@gao.gov

Acknowledgments

Kathy Larin, Assistant Director, and Janet Mascia, Analyst-in-Charge, managed this assignment. Lawrance Evans, Ben Bolitzer, Ken Bombara, Amanda Seese, and Rhiannon Patterson made significant contributions throughout the assignment. Charles Willson, Susannah Compton, and Patrick DiBattista helped develop the message for the report and testimony.

In addition, Doug Besharov, Dr. Maria Cancian, Dr. Sheldon Danziger, and Dr. Lawrence Mead reviewed and provided comments on the report on which this testimony is based. 
This is a work of the U.S. government and is not subject to copyright protection in the United States. It may be reproduced and distributed in its entirety without further permission from GAO. However, because this work may contain copyrighted images or other material, permission from the copyright holder may be necessary if you wish to reproduce this material separately. 
The Government Accountability Office, the audit, evaluation and investigative arm of Congress, exists to support Congress in meeting its constitutional responsibilities and to help improve the performance and accountability of the federal government for the American people. GAO examines the use of public funds; evaluates federal programs and policies; and provides analyses, recommendations, and other assistance to help Congress make informed oversight, policy, and funding decisions. GAO's commitment to good government is reflected in its core values of accountability, integrity, and reliability.

Obtaining Copies of GAO Reports and Testimony

\section{Order by Mail or Phone}

The fastest and easiest way to obtain copies of GAO documents at no cost is through GAO's Web site (www.gao.gov). Each weekday, GAO posts newly released reports, testimony, and correspondence on its Web site. To have GAO e-mail you a list of newly posted products every afternoon, go to www.gao.gov and select "Subscribe to Updates."

The first copy of each printed report is free. Additional copies are $\$ 2$ each. A check or money order should be made out to the Superintendent of Documents. GAO also accepts VISA and Mastercard. Orders for 100 or more copies mailed to a single address are discounted 25 percent. Orders should be sent to:

U.S. Government Accountability Office

441 G Street NW, Room LM

Washington, D.C. 20548

To order by Phone: Voice: (202) 512-6000

TDD: (202) 512-2537

Fax: (202) 512-6061

\section{To Report Fraud, Waste, and Abuse in Federal Programs}

\section{Contact:}

Web site: www.gao.gov/fraudnet/fraudnet.htm

E-mail: fraudnet@gao.gov

Automated answering system: (800) 424-5454 or (202) 512-7470

Gloria Jarmon, Managing Director, JarmonG@gao.gov (202) 512-4400 U.S. Government Accountability Office, 441 G Street NW, Room 7125 Washington, D.C. 20548 